\title{
1
}

\section{Delta Challenges and Trade-Offs from the Holocene to the Anthropocene}

\author{
Robert J. Nicholls, W. Neil Adger, Craig W. Hutton \\ and Susan E. Hanson
}

\subsection{Introduction}

The human dominance of the Earth and its implications is now captured in the concept of a fundamental transition to the Anthropocene. The Anthropocene represents a period of time when humans are the dominant influence on the climate and environment, as opposed to earlier periods more dominated by natural processes (Steffen et al. 2011; Ribot 2014;

R. J. Nicholls $(\square)$. S. E. Hanson

School of Engineering, University of Southampton, Southampton, UK e-mail: r.j.nicholls@soton.ac.uk

W. N. Adger

Geography, College of Life and Environmental Sciences, University of Exeter, Exeter, UK

C. W. Hutton

GeoData Institute, Geography and Environmental Science,

University of Southampton, Southampton, UK

(C) The Author(s) 2020 
Goudie and Viles 2016; Verburg et al. 2016; Donges et al. 2017). This transition to human domination is increasingly placed in the mid-twentieth century, though subject to vigorous debate. In this book, the focus is what the Anthropocene means for environmental management and achievement of the widely agreed goals of sustainable development (Hutton et al. 2018; Szabo et al. 2018), using deltas as hotspots where natural processes and intense and growing human activity intersect (Renaud et al. 2013).

Many relevant processes of environmental, economic and social change are progressing faster and more intensely in deltas than their global averages (Table 1.1). As humans have occupied deltas for centuries and millennia, they are, in effect, a bell-weather for the earth and the Anthropocene. Figure 1.1 illustrates some key features of deltas in the Anthropocene.

Deltas have formed at the land-sea interface over hundreds and thousands of years where large rivers deposit their sediment load creating extensive highly productive and low-lying coastal plains (Ibáñez et al. 2019). Natural deltas represent the interplay of sediment delivery and reworking, destructive marine processes and subsidence, including major river channel migration and switching (Syvitski 2008). With their extensive ecosystem services and accessible transport links, deltas have also been a focus for human settlement for millennia (Bianchi 2016). Their populations have grown dramatically in the past 100 years and today

Table 1.1 Key trends across deltas and globally, indicating a greater intensity in populated deltas

\begin{tabular}{lll}
\hline Issue & Delta trend & Global trend \\
\hline Population & $\wedge \wedge$ & $\wedge \wedge$ \\
Economy & $\wedge \wedge$ & $\wedge$ \\
Cities and urban areas & $\wedge \wedge$ & $\wedge$ \\
Migration & $\wedge \wedge$ & $\wedge$ \\
Intensification of land use & $\wedge \wedge$ & $\wedge$ \\
Biodiversity & $\vee \vee$ & $\vee$ \\
Threat of submergence & $\wedge \wedge$ & $\mathrm{N} / \mathrm{A}$ \\
Household adaptation & $?$ & $?$ \\
Engineering interventions & $\wedge \wedge$ & $\wedge$ \\
\hline
\end{tabular}

$\wedge$ increasing; $\wedge \wedge$ strongly increasing; $\vee$ decreasing; $\vee \vee$ strongly decreasing; ? no data/unclear; N/A—not applicable 

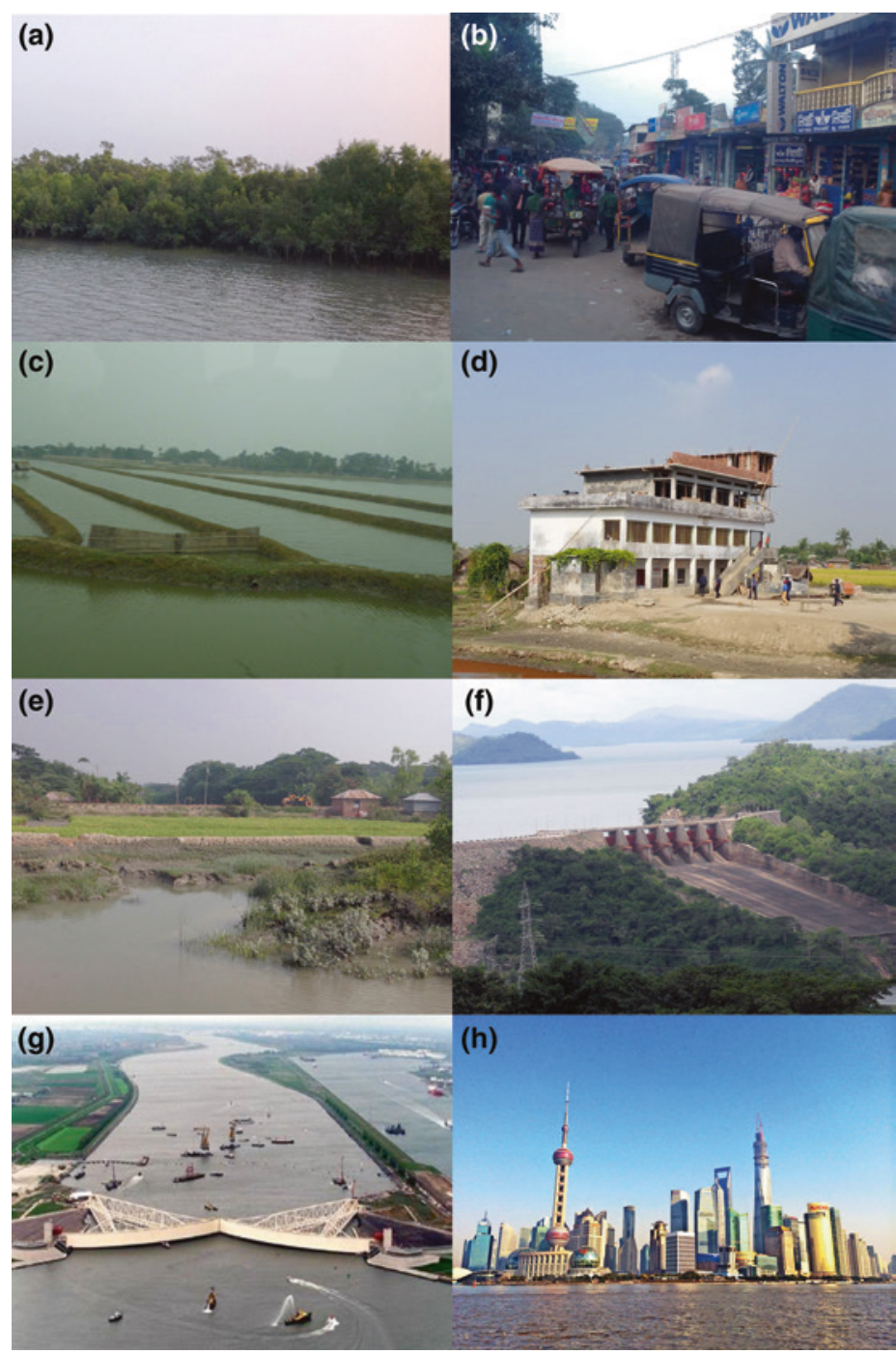

Fig. 1.1 Some delta features in the Anthropocene. a Natural environmentsThe Sunderbans, a world heritage site, India. b A delta city, Khulna, Bangladesh. c Intensive aquaculture, Bangladesh. d Cyclone evacuation centre, Bangladesh. e Agriculture-Polders, Bangladesh. $f$ Major infrastructure-Akosombo Dam, upstream of the Volta Delta, Ghana. g Adaptation-A major storm surge barrier-the Maeslantkering, The Netherlands. h A world delta city, Shanghai, China (Photos: a, b, e Robert J Nicholls; c, $\mathbf{d}$ Attila N Lázár; $\mathbf{f}, \mathbf{g}, \mathbf{h}$ reprinted under licence CC BY-SA 1.0 and 3.0) 
more than 500 million people live in and around deltas globally: or seven per cent of the human population on one per cent of global land area (Ericson et al. 2006; Woodroffe et al. 2006). Most large delta populations are found in mid and low latitude deltas in the global South associated with large rural populations depending on agriculture for their livelihoods, especially in Asia. Many deltas are also associated with large and rapidly growing mega-cities such as Cairo, Dhaka, Kolkata and Shanghai.

With their large populations and economic opportunities, deltas are a key focus for development. Deltas have also been associated with the threat of climate-induced sea-level rise and subsidence and there is concern this could act as a brake on economic development (de Souza et al. 2015; Hallegatte et al. 2016). Due to the low elevation of deltas, small changes in water level can have profound hydrological effects, including inundation, salinity and waterlogging with severe impacts on livelihoods. In the extreme, the spectre of mass forced migration from deltas due to sea-level rise was raised 30 years ago (Milliman et al. 1989). However, while such projections have become received wisdom and widely repeated (Gemenne 2011), there has been little systematic scientific investigation of demographic realities of future population movements and settlement patterns. Most integrated analyses show the complexity of delta processes and the occurrence of multiple and interacting drivers of change (Tessler et al. 2015; Nicholls et al. 2016). This book examines the current and future trajectories of Anthropocene deltas by focussing on the full range of interrelated environmental and social dynamics. It aims to understand the opportunities as well as the threats in deltas under Anthropocene conditions.

\subsection{Trends in Deltas, Their Catchments and Adjacent Areas}

There are deltas in every inhabited continent in the world, as illustrated in Fig. 1.2. There is a strong concentration of densely populated deltas in south, south-east and east Asia. Based on Woodroffe et al. (2006), the largest delta by population is the 


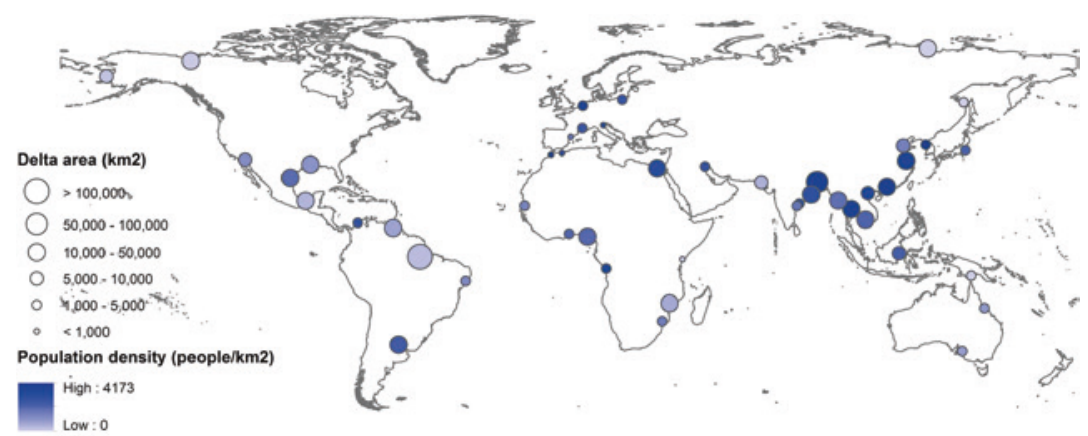

Fig. 1.2 A map of 47 global deltas by size and population density (based on data in Dunn 2017)

Ganges-Brahmaputra-Meghna (GBM) Delta (India and Bangladesh) with more than 130 million inhabitants. The other eight significant and populous deltas around the Himalayas, the Irrawaddy (Myanmar), Chao Phayra (Thailand), Mekong (Vietnam), Song Hong (Red) (Vietnam), Pearl (China), Changjiang (China), Huanghe (China) and the abandoned Huanghe (Jiangsu) (China); an additional 195 million people, living at densities of $400-5000$ people $/ \mathrm{km}^{2}$. Further large delta populations are found along the Indian coast of the Bay of Bengal coast, for example the Mahanadi, as well as in Indonesia where many small deltas exist and coalesce into a coastal plain with dense populations, as in Java. Outside Asia there are deltas in Europe, the Netherlands is a delta country; North America, the Mississippi is an iconic delta; and South America, where the world's largest delta in area, the Amazon, is located. Africa has the vital Nile Delta, which supports around 40 million people including the city of Cairo, and a number of smaller locally important deltas such as the Volta in Ghana.

Deltas have been changing rapidly over the last few decades. They naturally evolve by the interplay of sediment supply, redistribution and loss, including the natural subsidence that occurs in all deltas. Hence, some deltas may experience accretion in certain areas and erosion elsewhere related to the local sediment budget (see Chapter 2). In the Anthropocene, a range of additional processes induced by humans have operated across scales as summarised in Table 1.2. 
Table 1.2 Major human processes shaping delta evolution by scale

\begin{tabular}{lll}
\hline Scale & Human-induced process & $\begin{array}{l}\text { Sources/information in this } \\
\text { book }\end{array}$ \\
\hline Global & Climate change and & Chapter 6 \\
& sea-level rise & \\
& Globalisation, trade & Chapter 8 \\
and world markets & \\
Catchment & Land use change and & Syvitski et al. (2009); Chapter 5 \\
& sediment yield & \\
& Dams construction and & \\
& increased water & \\
& (and sediment) retention & \\
Enhanced subsidence & Ericson et al. (2006), Syvitski \\
(due to ground fluid with- & et al. (2009), Tessler et al. \\
drawal and/or drainage) & (2018); Chapter 5 \\
& Enhanced flood protection & Syvitski et al. (2009); \\
& (stopping sedimentation) & Chapters 5, 9 and 10 \\
& Urbanisation and & Szabo et al. (2016a); \\
& associated infrastructure & Chapters 7-9 \\
& Intensified agriculture & Chapters 6, 8 and 9 \\
& and aquaculture & \\
\hline
\end{tabular}

At the global scale, human-induced climate change threatens deltas with accelerating sea-level rise, with more intense storms being of particular concern. These effects will be much larger in the future. Indirectly, deltas are also exposed to global markets and trends and this can drive changes at smaller scales, such as the growth in shrimp aquaculture for export. At the regional and catchment scale, human changes in the catchments, such as dams, can change the delivery of water and reduce the supply of sediment, sometimes almost completely. Hydrological effects in deltas are also apparent with issues such as intensified saltwater intrusion during the dry season reflecting multiple factors including upstream changes, delta changes and sea-level rise (e.g. Nicholls et al. 2018b). Deltas have long been important food producers reflecting their significant productive ecosystem services. With growing populations, agriculture has been greatly intensified in deltas for local and wider use, as has aquaculture. This is widely associated with polderisation where low-lying areas are surrounded by dykes and drainage is improved, allowing more easy regulation of water levels and excluding natural flooding 
and sedimentation. Agriculture intensification leads to less subsistence agriculture and lower agriculture employment (e.g. Amoako-Johnson et al. 2016). Agricultural systems often require intensive irrigation infrastructure to manage water during dry periods. Drainage and fluid withdrawal leads to accelerated subsidence and falling land levels increase the likelihood of waterlogging and flooding, driving the construction or upgrade of flood defences. Most populous deltas in the most recent decades have also experienced major rural to urban migration and growing urban centres, within or adjacent to the delta (Szabo et al. 2016a). The urbanisation trend has led to major infrastructure demands including enhanced urban flood management and protection. Consequently, deltas are widely moving towards being highly engineered landscapes and are now a long way from their previous natural or semi-natural state.

Figure 1.3 contrasts an archetypal pristine versus an Anthropocene delta, emphasising the intensification of a wide range of human activities in the Anthropocene delta. In the real world, deltas are at different stages of these processes, but all deltas with significant populations, it is argued, are following similar trajectories. The incremental nature of many of the trends is also apparent: they accumulate with time such as sea-level rise, loss of elevation and growth of flood defences (Tessler et al. 2015). There is also a strong coupling between natural processes and engineering responses that can lead to co-evolution and lock-in (Welch et al. 2017). Hence, deltas are complex systems and historical precedent is no longer a guide to the future. Adaptation and flexibility to the seasons and to climate extremes have always been necessary features of successful human occupancy of deltas. However, many historic adaptation behaviours may no longer be fit for purpose, due to changing pressures and climatic changes outside of lived experience.

For the future, climate change and sea-level rise have long been recognised as a major threat to deltas (Milliman et al. 1989; Tsyban et al. 1990). However, deltas in the Anthropocene are influenced by much more than climate change. Catchment changes, large-scale engineering interventions in rivers and coasts, population dynamics and socio-ecological interactions dominate virtually all observed changes in the major deltas of the world to date. These factors can only be compounded by climate change and sea-level rise which is a growing issue, especially after 2050 when 


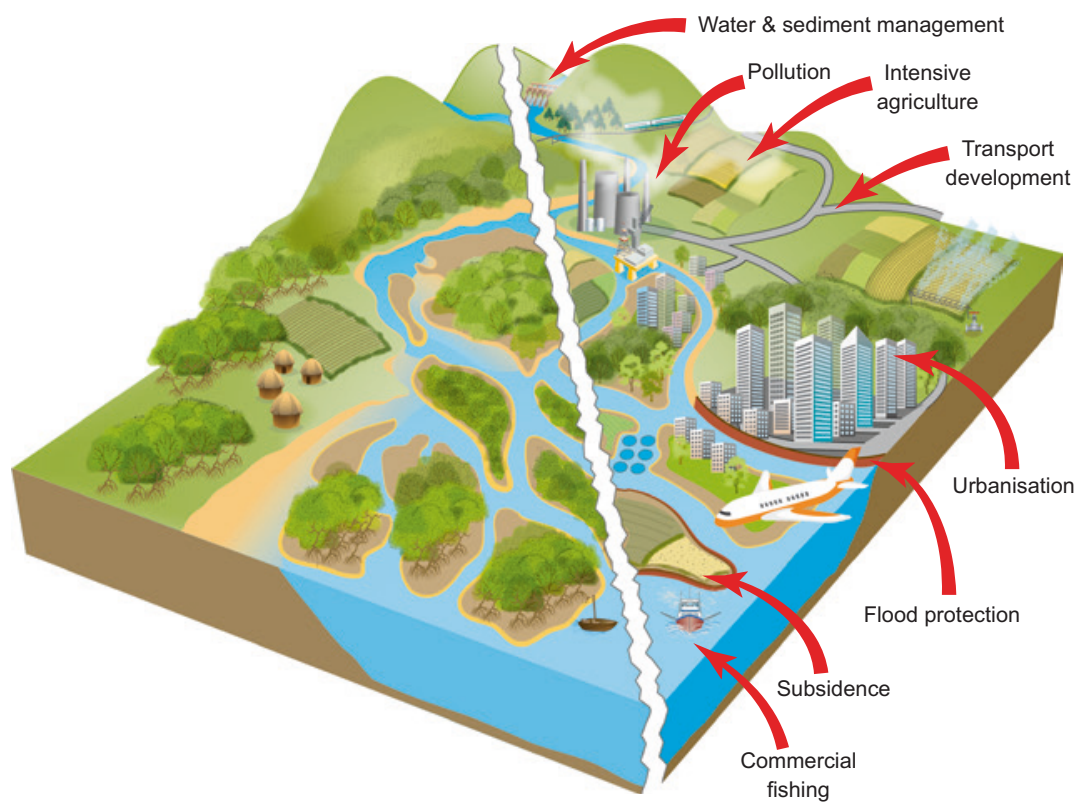

Fig. 1.3 A pristine (left) and an Anthropocene (right) archetypal delta, emphasising the intensification of a wide range of human activities within deltas during the Anthropocene

changes could be dramatic (Brown et al. 2018; Nicholls et al. 2018a). Consequently, as the Anthropocene continues, societies will be transformed and will need to address new and emerging threats and challenges. In many ways, delta societies and regions epitomise the challenges found elsewhere: the lessons drawn from deltas can inform the needs in other settings.

\subsection{Possible Consequences of Changing Deltas}

Current and future Anthropocene trends and trajectories have important consequences for the deltas and their populations. For example, the geomorphic trend of loss of elevation leads to potential submergence of the deltas and land loss or a growing dependence on flood defences and pumped drainage (Blum and Roberts 2009; Syvitski et al. 2009). This 
trend is apparent in many deltas around the world, related to subsidence and sea-level rise. However, as sea-level rise accelerates and compensating sediment supplies continue to fall, an existential threat to deltas is likely to occur in the Anthropocene. Relative sea-level rise also has important hydrological trends, especially waterlogging and salinisation (Payo et al. 2017) with potential consequences for agriculture even if there are flood defences.

Deltas have rich biodiversity and wider ecosystem service values. The pressure from expanding population, agriculture, industrial development and submergence is removing the space for this important characteristic of deltas. At the same time, there is more interest in 'working with nature' management approaches, such as mangrove buffers, which might give space for biodiversity and their ecosystem services. But are delta societies willing to give up that space? Diversification to high value crops has increased the value of agriculture. Moreover, subsistence agriculture is increasingly less attractive as the economies diversify and relative wages and returns to labour in primary industries stagnate. Climate change is also making traditional agriculture more risky and less attractive, suggesting a trend to decline in employment in agriculture and consolidation of agricultural holdings. These trends in the nature of agriculture and land use represent a profound change to deltas globally. Moreover, dyke-based delta management and the move away from annual floods may undermine agricultural economics due to the high cost of fertiliser, as shown in the Mekong Delta (Chapman and Darby 2016). It is not clear who will benefit from these agriculture transitions or from rapid diversification of rural economies in delta regions and urbanisation. For example, the economy of Bangladesh is currently growing at more than seven per cent, and over the past 20 years the economy has increased five times, according to World Bank data. These observed changes indicate the nature of the delta economies are likely to continue to change fundamentally in the coming decades.

In addition, there are major demographic transitions in societies in most countries with large populous deltas (Szabo et al. 2016a). This suggests the emergence of ageing and stable and even falling populations in the future. The growth of cities in and around the deltas has been profound and reflects a large migration of people from rural areas. 
Data from observations and projections of populations of selected large cities from 1950 to 2020 (Table 1.3) shows the largest growth in the GBM Delta, especially in Dhaka, Kolkata and Chattogram (also known as Chittagong), and in relative terms Dhaka, Bhubaneswar and Lomé. Continued substantial growth is projected from 2020 to 2035 in all the cities, except Khulna. When considering the effects of climate change on migration, this demonstrates existing substantial high levels of mobility and population dynamics in many deltas.

\subsection{Policy Implications}

The sustainability of deltas in the Anthropocene requires the long term health of physical and ecological systems alongside widely distributed development that leaves no-one behind. Day et al. (2016) consider delta sustainability within the context of global biophysical and socio-economic constraints. They state that geomorphic, ecological and economic aspects of the delta sustainability are strongly influenced by society. However, critical factors of a sustainable delta society include livelihood sustainability, demography, well-being and critically their trajectories through time. The process of managing deltas will require an adaptive approach to the development of policy with an effective strategy for monitoring progress, scenario development and learning. Taken together

Table 1.3 Selected observed and projected city populations (thousands) in and adjacent to deltas from 1950 to 2035 (Data from UN DESA [2018]) (see Fig. 1.4 and Table 1.4)

\begin{tabular}{lllllll}
\hline City & 1950 & 1970 & 1990 & 2010 & 2020 & 2035 \\
\hline Accra & 177 & 631 & 1197 & 2060 & 2514 & 3632 \\
Lomé & 33 & 192 & 619 & 1466 & 1828 & 2947 \\
Bhubaneswar & 16 & 98 & 395 & 868 & 1163 & 1649 \\
Kolkata & 4604 & 7329 & 10,974 & 14,003 & 14,850 & 19,564 \\
Khulna & 61 & 310 & 985 & 1098 & 954 & 1213 \\
$\begin{array}{l}\text { Dhaka } \\
\text { Chattogram }\end{array}$ & 336 & 1374 & 6621 & 14,731 & 21,006 & 31,234 \\
(Chittagong) & 289 & 723 & 2023 & 4106 & 5020 & 7110 \\
\hline
\end{tabular}


these diverse elements represent the challenges of delta planning in the Anthropocene.

The complexity and intensity of the changes discussed in Sects. 1.2 and 1.3 suggests that management and development in deltas will be challenging. Inevitably important choices and trade-offs will emerge and there will be a need for clear priorities and goals. This is apparent when the aspirations of the UN Sustainable Development Goals (SDGs) are considered, as the issues of trade-offs and choice and how these challenges are addressed have received little attention (Szabo et al. 2016b; Hutton et al. 2018). While delta residents have had to be highly adaptive to exploit delta livelihoods, all the changes above suggest that traditional adaptation will be insufficient and important new adaptation efforts linked to delta development will be required in the future.

The scale of the challenge for delta management in the Anthropocene would suggest that new and more integrated approaches are required. Deltas are inherently challenging systems to manage due to the high sensitivity to multiple drivers and the potential for co-evolution and lock-in (Welch et al. 2017; Seijger et al. 2018). As an example, construction of flood defences and drainage attracts development, excludes sedimentation and promotes subsidence of organic soils, increasing the consequences of flooding if the defences fail. Hence, construction of flood defences ultimately promotes bigger and higher defences and the consequences of failure grow. Hallegatte et al. (2013) analysed flooding in coastal cities and found protection resulted in fewer, but bigger, disasters in terms of economic damage. This effect was largest in cities located in deltas as they subside, in addition to experiencing climate-induced sea-level rise. More innovative ways of managing deltas are needed such as allowing controlled flooding and sedimentation. This approach has been used in the Yellow River, China (Han et al. 1995) and is applied at a small scale as so-called Tidal River Management in Bangladesh (Chapters 2, 6 and 10). A major dilemma for such strategies is whether they can be scaled up for Anthropocene conditions when sediment supply from feeding rivers is widely diminishing (e.g. Rogers and Overeem 2017; Dunn et al. 2018).

Whole delta plans aim to consider the entire delta and adopt integrated perspectives. They are proliferating. In the Mississippi Delta, 
coastal restoration is actively focussing on ecosystem restoration and coastal safety (CPRAL 2017). In the Netherlands, the Dutch Delta Commission has been established and similar plans are being developed in the Mekong and Bangladesh (Seijger et al. 2017). In all these examples, there is a vision of coordinated delta development and adaptive approaches to an uncertain future.

\subsection{The Book Approach and Structure}

This book assesses the influences and interactions in deltas in order to appraise the sustainability and potential futures for deltas in the Anthropocene. It draws significantly from research conducted in the multi-disciplinary Deltas, Vulnerability and Climate Change: Migration and Adaptation project that researched a diversity of the world's deltas from 2014 to 2018 (DECCMA 2018). The DECCMA initiative generated scenarios of downscaled climate change and sea-level rise; analysed hotspots of vulnerability and risk; examined individual behaviour around adaptation practices and migration patterns and consequences; developed land cover and national agro-ecological zone production; and modelled the macroeconomy of deltas with projections of how environmental change would affect both the scale of economic activity and demand for labour. The book, building on findings of the DECCMA consortium, seeks to answer a number of questions. What are the key characteristics of the Anthropocene economic transition in deltas? What are the implications of this transition for twenty-first-century management and adaptation of deltas, including the wider policy implications? Do deltas offer an early insight into the impact of the Anthropocene transition of relevance to the management for other socio-ecological contexts?

The chapters and individual assessments draw on new empirical insights from DECCMA based on primary data and analysis for three significant and contrasting deltas: the world's largest and most populous delta, the GBM, spanning India and Bangladesh, the Mahanadi, entirely within India and the Volta in West Africa (Fig. 1.4). They also draw on a renewed and vigorous global community of researchers 


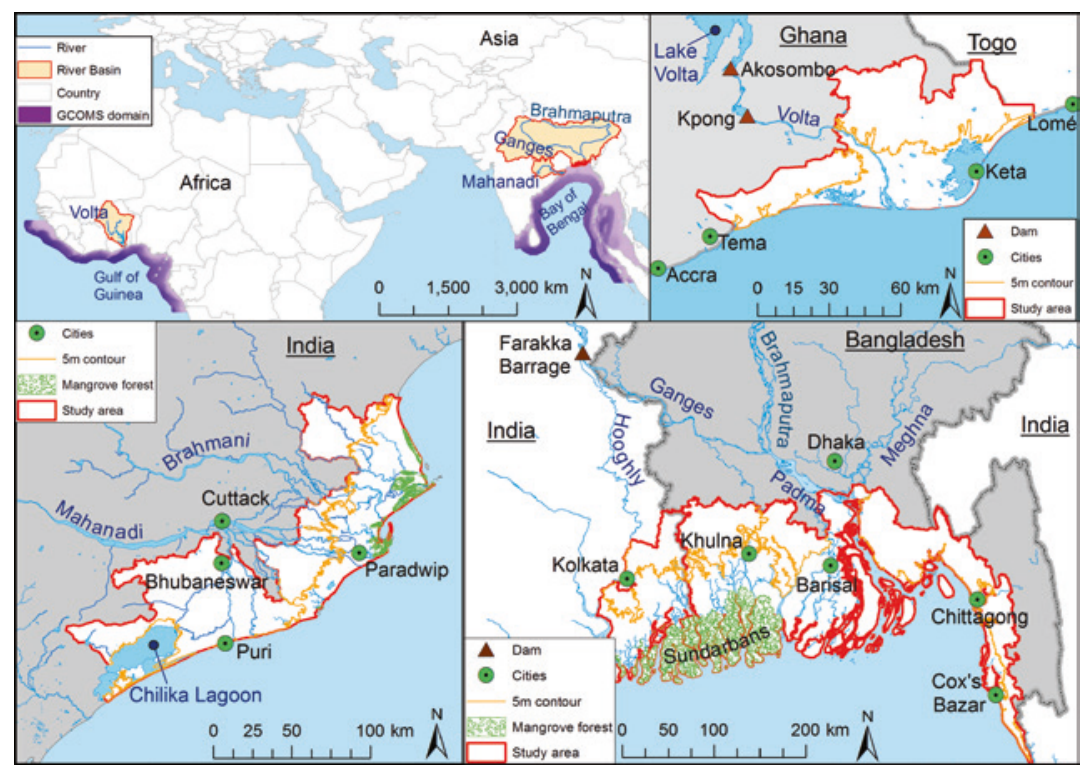

Fig. 1.4 Delta regions considered, including their associated catchments and the shelf sea regions (analysed for fisheries): a Volta Delta. b Mahanadi Delta. c GangesBrahmaputra-Meghna Delta (Modified from Kebede et al. [2018] under CC BY 4.0)

seeking to support delta planning through integrated science. Deltas can be defined in various ways, such as the location of the most upstream distributary, or the surface area composed of Holocene sediments (e.g. Woodroffe et al. 2006). The principal focus of analysis in this book is on the coastal portion of deltas. Coastal parts of deltas are the crucible of the impacts of climate change, especially sea-level rise and subsidence, as well as areas with high population density and economic activity. The study areas for the DECCMA deltas were defined as a subset of the physical delta limited to land below the five-metre contour. The specific study area was defined by selecting all the administrative units within this physical delta, i.e. the political units where these impacts and adaptation are experienced and represent dilemmas and trade-offs. In Bangladesh, a slightly different approach was taken and the coastal zone, as recognised by the Government of Bangladesh, was analysed. This excludes large areas in Bangladesh below the 
five-metre contour further inland, but gives an administratively meaningful study area. This is also the area subject to tropical cyclones. Some of the key characteristics of the delta study areas are given in Table 1.4.

The population density is lowest in the Volta and exceeds 1000 people $/ \mathrm{km}^{2}$ in the dominantly rural setting of the GBM Delta. The deltas all contain large and growing cities, or are adjacent to such cities, with Accra and Lomé on either side of the Volta Delta. Agriculture and fisheries are important components of the economy, especially employment. However, the economies are more diverse than often considered, with large industry and construction, and especially service components, although these aspects of the economy have a strong linkage to agriculture and fisheries.

The multi-disciplinary, policy-orientated research reported throughout the book explores the effects of a range of environmental and economic scenarios on migration, adaptation, governance, as well as asset poverty, agricultural and fisheries productivity and nutritional levels. The research is strongly aligned to the United Nation's SDGs as delta populations often experience extremes of poverty, gender and structural inequality, variable levels of health and well-being, while being vulnerable to extreme and systematic environmental and climate change.

The book is structured as follows. First, the three deltas are considered in detail in Chapters 2-4: the GBM, Mahanadi and Volta Deltas, respectively. They ask the questions, how are these deltas today, and what does the Anthropocene mean for each of them? Six thematic chapters then explore challenges of development and delta futures, based on global evidence and drawing from the DECCMA example deltas in particular. Chapter 5 considers fluvial sediment supply and relative sea-level change in deltas. This is the process which produced and sustained the world's deltas over the last few millennia and centuries. However, in the Anthropocene the sediment supply is failing due to upstream change, especially the construction of dams. This suggests intensified hazards and growing land loss, or a growing dependence on dykes and polders. Only radical management in the deltas and in the catchments can change this trend. Chapter 6 examines the hazards, exposure, vulnerability and risks within deltas, and their spatial expression, including recognising hotspots. These concepts have emerged 


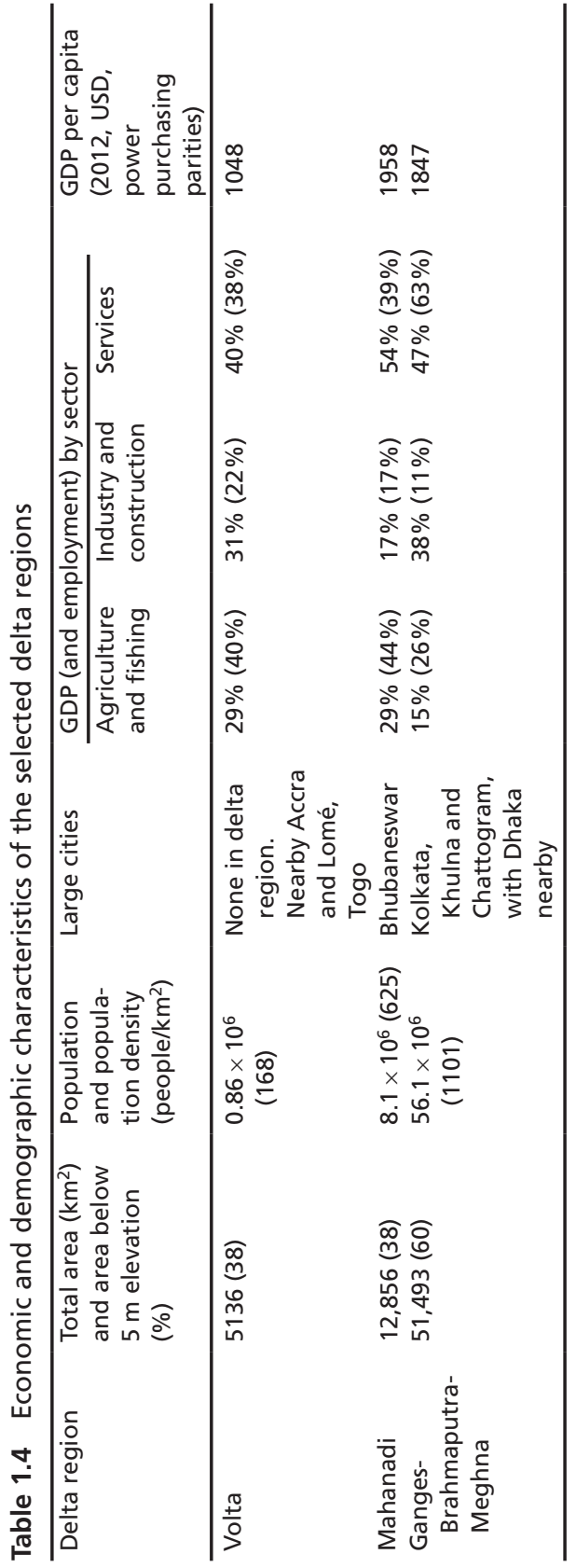


over the last few decades as key information for environmental policy analysis. Hotspots also inform other analysis and helped to guide the analysis of migration in Chapter 7 and adaptation in Chapter 9. Chapter 7 assesses where people live and move within deltas using analysis of the census and dedicated household surveys. It finds that there is high human mobility in deltas today driven largely by economic reasons, including movement to cities. Hence, any migration due to environmental change will be in addition to the existing migration processes. Chapter 8 focuses on delta economics and sustainability. While agriculture is a large part of the economy, and provides much of the employment, the three delta economies have growing service, trade-transport, industry and construction sectors. Fisheries are also important. Nonetheless, the delta economies are quite vulnerable to climate change impacts in the next few decades. Chapter 9 considers adaptation to change as a response to these and other threats. Adaptation is already widespread in deltas. Much of the adaptation activity at household level focusses on reducing past and present vulnerabilities, with little attention to longer term risks. Government adaptation initiatives often address structural needs and managing the dynamic nature of these environments. There is no joined up vision of adaptation in deltas as yet, although future adaptation offers delta societies opportunities and choices to deal with the challenges of the Anthropocene, and it is important to recognise that adaptation choices will shape the future evolution of deltas. Chapter 10 assesses adaptation at the delta scale, and the role of trade-offs and plausible development pathways. Delta management in the Anthropocene will involve the consideration of trade-offs and the balancing of positive and negative outcomes for delta functions and the societies that rely on them. Using integrated models, the chapter demonstrates that trade-offs are crucial governance challenges for the future sustainability of deltas, probably illustrating a wider challenge for the Anthropocene. Lastly, Chapter 11 synthesises the book, considering the questions posed for deltas in the Anthropocene. The trends emerging in each chapter are reviewed and considered together, and possible trajectories for the Volta, Mahanadi and GBM deltas are presented. Using these insights, it considers the 
notion of a sustainable delta from a variety of perspectives, and what this might mean under Anthropocene conditions.

These chapters examine deltas from a range of biophysical and socio-economic perspectives. The consideration of migration and population in deltas in Chapters 7 and 9, for example, uses a new and bespoke survey on migration and adaptation patterns across the DECCMA deltas: the survey involved more than 7500 households and individual migrants in rural parts of the deltas and in their destination cities (DECCMA 2018). Such data on migration and household-level adaptation to hazards and climate changes provides important new insights on delta demography and human dilemmas in Anthropocene deltas. Analysis of the delta economy in Chapter 8 uses newly developed macroeconomic models for the DECCMA deltas that allows direct comparative analysis of the macro-level trends and impacts of environmental change on economic activity. Synthesis across all these dimensions provides important new insights on key challenges and trade-offs for delta societies in the Anthropocene.

\section{References}

Amoako-Johnson, F., Hutton, C. W., Hornby, D., Lázár, A. N., \& Mukhopadhyay, A. (2016). Is shrimp farming a successful adaptation to salinity intrusion? A geospatial associative analysis of poverty in the populous Ganges-Brahmaputra-Meghna Delta of Bangladesh. Sustainability Science, 11(3), 423-439. https://doi.org/10.1007/s11625-016-0356-6.

Bianchi, T. S. (2016). Deltas and humans: A long relationship now threatened by global change. Oxford, UK: Oxford University Press.

Blum, M. D., \& Roberts, H. H. (2009). Drowning of the Mississippi Delta due to insufficient sediment supply and global sea-level rise. Nature Geoscience, 2, 488. https://doi.org/10.1038/ngeo553.

Brown, S., Nicholls, R. J., Lázár, A. N., Hornby, D. D., Hill, C., Hazra, S., et al. (2018). What are the implications of sea-level rise for a 1.5, 2 and 3 ${ }^{\circ} \mathrm{C}$ rise in global mean temperatures in the Ganges-Brahmaputra-Meghna and other vulnerable deltas? Regional Environmental Change, 18(6), 18291842. https://doi.org/10.1007/s10113-018-1311-0. 
Chapman, A., \& Darby, S. (2016). Evaluating sustainable adaptation strategies for vulnerable mega-deltas using system dynamics modelling: Rice agriculture in the Mekong Delta's An Giang Province. Vietnam. Science of the Total Environment, 559, 326-338. https://doi.org/10.1016/j. scitotenv.2016.02.162.

CPRAL. (2017). Louisiana's comprehensive master plan for a sustainable coast: Commited to our coast. Baton Rouge, LA: Coastal Protection and Restoration Authority of Louisiana. http://coastal.la.gov/wp-content/ uploads/2017/04/2017-Coastal-Master-Plan_Web-Single-Page_CFinalwith-Effective-Date-06092017.pdf. Last accessed 20 December 2018.

Day, J. W., Agboola, J., Chen, Z., D’Elia, C., Forbes, D. L., Giosan, L., et al. (2016). Approaches to defining deltaic sustainability in the $21 \mathrm{st}$ century. Estuarine, Coastal and Shelf Science, 183, 275-291. https://doi. org/10.1016/j.ecss.2016.06.018.

DECCMA. (2018). Climate change, migration and adaptation in deltas: Key findings from the DECCMA project (Deltas, Vulnerability and Climate Change: Migration and Adaptation [DECCMA] Report). Southampton, UK: DECCMA Consortium. https://www.preventionweb.net/publications/ view/61576. Last accessed 27 November 2018.

de Souza, K., Kituyi, E., Harvey, B., Leone, M., Murali, K. S., \& Ford, J. D. (2015). Vulnerability to climate change in three hot spots in Africa and Asia: Key issues for policy-relevant adaptation and resilience-building research. Regional Environmental Change, 15(5), 747-753. https://doi. org/10.1007/s10113-015-0755-8.

Donges, J. F., Winkelmann, R., Lucht, W., Cornell, S. E., Dyke, J. G., Rockström, J., et al. (2017). Closing the loop: Reconnecting human dynamics to Earth System science. The Anthropocene Review, 4(2), 151-157. https://doi.org/10.1177/2053019617725537.

Dunn, F. E. (2017). Multidecadal fluvial sediment fluxes to major deltas under environmental change scenarios: Projections and their implications (PhD thesis). Faculty of Geography and the Environment, University of Southampton, Southampton, UK.

Dunn, F. E., Nicholls, R. J., Darby, S. E., Cohen, S., Zarfl, C., \& Fekete, B. M. (2018). Projections of historical and 21st century fluvial sediment delivery to the Ganges-Brahmaputra-Meghna, Mahanadi, and Volta deltas. Science of the Total Environment, 642, 105-116. https://doi.org/10.1016/j. scitotenv.2018.06.006.

Ericson, J. P., Vörösmarty, C. J., Dingman, S. L., Ward, L. G., \& Meybeck, M. (2006). Effective sea-level rise and deltas: Causes of change and human 
dimension implications. Global and Planetary Change, 50(1-2), 63-82. https://doi.org/10.1016/j.gloplacha.2005.07.004.

Gemenne, F. (2011). Why the numbers don't add up: A review of estimates and predictions of people displaced by environmental changes. Global Environmental Change, 21, S41-S49. https://doi.org/10.1016/j. gloenvcha.2011.09.005.

Goudie, A. S., \& Viles, H. A. (2016). Geomorphology in the Anthropocene. Cambridge, UK: Cambridge University Press.

Hallegatte, S., Bangalore, M., Bonzanigo, L., Fay, M., Kane, T., Narloch, U., et al. (2016). Shock waves: Managing the impacts of climate change on poverty. Washington, DC: World Bank. https://openknowledge.worldbank.org/handle/10986/22787. License: CC BY 3.0 IGO.

Hallegatte, S., Green, C., Nicholls, R. J., \& Corfee-Morlot, J. (2013). Future flood losses in major coastal cities. Nature Climate Change, 3, 802-806. https://doi.org/10.1038/nclimate1979.

Han, M., Wu, L., Hou, C., \& Liu, G. (1995). Sea-level rise and the North China coastal plain: A preliminary analysis. Journal of Coastal Research, S14, $132-150$.

Hutton, C. W., Nicholls, R. J., Lázár, A. N., Chapman, A., Schaafsma, M., \& Salehin, M. (2018). Potential trade-offs between the Sustainable Development Goals in Coastal Bangladesh. Sustainability, 10(4), 1008. http://dx.doi.org/10.3390/su10041108.

Ibáñez, C., Alcaraz, C., Caiola, N., Prado, P., Trobajo, R., Benito, X., et al. (2019). Basin-scale land use impacts on world deltas: Human vs natural forcings. Global and Planetary Change, 173, 24-32. https://doi. org/10.1016/j.gloplacha.2018.12.003.

Kebede, A. S., Nicholls, R. J., Allan, A., Arto, I., Cazcarro, I., Fernandes, J. A., et al. (2018). Applying the global RCP-SSP-SPA scenario framework at sub-national scale: A multi-scale and participatory scenario approach. Science of the Total Environment, 635, 659-672. https://doi.org/10.1016/j. scitotenv.2018.03.368.

Milliman, J. D., Broadus, J. M., \& Gable, F. (1989). Environmental and economic implications of rising sea level and subsiding deltas: The Nile and Bengal examples. Ambio, 18(6), 340-345.

Nicholls, R. J., Brown, S., Goodwin, P., Wahl, T., Lowe, J., Solan, M., et al. (2018a). Stabilization of global temperature at $1.5^{\circ} \mathrm{C}$ and $2.0^{\circ} \mathrm{C}$ : Implications for coastal areas. Philosophical Transactions of the Royal Society, 376(2119). https://doi.org/10.1098/rsta.2016.0448. 
Nicholls, R. J., Hutton, C. W., Adger, W. N., Hanson, S. E., Rahman, M. M., \& Salehin, M. (Eds.). (2018b). Ecosystem services for well-being in deltas: Integrated assessment for policy analysis. London, UK: Palgrave Macmillan.

Nicholls, R. J., Hutton, C. W., Lázár, A. N., Allan, A., Adger, W. N., Adams, H., et al. (2016). Integrated assessment of social and environmental sustainability dynamics in the Ganges-Brahmaputra-Meghna Delta, Bangladesh. Estuarine and Coastal Shelf Science, 183, 370-381. https://doi. org/10.1016/j.ecss.2016.08.017.

Payo, A., Lázár, A. N., Clarke, D., Nicholls, R. J., Bricheno, L., Mashfiqus, S., et al. (2017). Modeling daily soil salinity dynamics in response to agricultural and environmental changes in coastal Bangladesh. Earth's Future, 5(5), 495-514. https://doi.org/10.1002/2016EF000530.

Renaud, F. G., Syvitski, J. P. M., Sebesvari, Z., Werners, S. E., Kremer, H., Kuenzer, C., et al. (2013). Tipping from the Holocene to the Anthropocene: How threatened are major world deltas? Current Opinion in Environmental Sustainability, 5(6), 644-654. https://doi.org/10.1016/j. cosust.2013.11.007.

Ribot, J. (2014). Cause and response: Vulnerability and climate in the Anthropocene. Journal of Peasant Studies, 41(5), 667-705. https://doi.org/1 $0.1080 / 03066150.2014 .894911$.

Rogers, K. G., \& Overeem, I. (2017). Doomed to drown? Sediment dynamics in the human-controlled floodplains of the active Bengal Delta. Elementa Science of the Anthropocene, 5, 65. https://doi.org/10.1525/elementa.250.

Seijger, C., Douven, W., van Halsema, G., Hermans, L., Evers, J., Phi, H. L., et al. (2017). An analytical framework for strategic delta planning: Negotiating consent for long-term sustainable delta development. Journal of Environmental Planning and Management, 60(8), 1485-1509. https://doi. org/10.1080/09640568.2016.1231667.

Seijger, C., Ellen, G. J., Janssen, S., Verheijen, E., \& Erkens, G. (2018). Sinking deltas: Trapped in a dual lock-in of technology and institutions. Prometheus, 35, 1-21. https://doi.org/10.1080/08109028.2018.1504867. Steffen, W., Persson, Å., Deutsch, L., Zalasiewicz, J., Williams, M., Richardson, K., et al. (2011). The Anthropocene: From global change to planetary stewardship. AMBIO: A Journal of the Human Environment, 40(7), 739-761. https://doi.org/10.1007/s13280-011-0185-x.

Syvitski, J. P. M. (2008). Deltas at risk. Sustainability Science, 3(1), 23-32. https://doi.org/10.1007/s11625-008-0043-3. 
Syvitski, J. P. M., Kettner, A. J., Overeem, I., Hutton, E. W. H., Hannon, M. T., Brakenridge, G. R., et al. (2009). Sinking deltas due to human activities. Nature Geoscience, 2(10), 681-686. https://doi.org/10.1038/ngeo629.

Szabo, S., Adger, W. N., \& Matthews, Z. (2018). Home is where the money goes: Migration-related urban-rural integration in delta regions. Migration and Development, 7(2), 163-179. https://doi.org/10.1080/21632324.2017 .1374506 .

Szabo, S., Brondizio, E., Renaud, F. G., Hetrick, S., Nicholls, R. J., Matthews, Z., et al. (2016a). Population dynamics, delta vulnerability and environmental change: Comparison of the Mekong, Ganges-Brahmaputra and Amazon delta regions. Sustainability Science, 11(4), 539-554. https://doi. org/10.1007/s11625-016-0372-6.

Szabo, S., Nicholls, R. J., Neumann, B., Renaud, F. G., Matthews, Z., Sebesvari, Z., et al. (2016b). Making SDGs work for climate change hotspots. Environment: Science and Policy for Sustainable Development, 58(6), 24-33. https://doi.org/10.1080/00139157.2016.1209016.

Tessler, Z. D., Vörösmarty, C. J., Grossberg, M., Gladkova, I., Aizenman, H., Syvitski, J., et al. (2015). Profiling risk and sustainability in coastal deltas of the world. Science, 349(6248), 638-643. https://doi.org/10.1126/science. aab3574.

Tessler, Z. D., Vörösmarty, C. J., Overeem, I., \& Syvitski, J. P. M. (2018). A model of water and sediment balance as determinants of relative sea level rise in contemporary and future deltas. Geomorphology, 305, 209-220. https://doi.org/10.1016/j.geomorph.2017.09.040.

Tsyban, A. V., Everett, J. T., \& Titus, J. G. (1990). World oceans and coastal zones. In W. Tegart, G. W. Sheldon, \& C. Griffiths (Eds.), Climate change: The IPCC impacts assessment. Canberra, Australia: Australian Government Publishing Service. http://papers.risingsea.net/federal_reports/IPCC-far_ wg_II_chapter_6.pdf. Last accessed 21 January 2019.

UN DESA. (2018). World Urbanization Prospects: The 2018 Revision (Online ed.). Department of Economic and Social Affairs, Population Division, United Nations. https://population.un.org/wup/Download/. Last accessed 2 January 2019.

Verburg, P. H., Dearing, J. A., Dyke, J. G., Leeuw, S., Seitzinger, S., Steffen, W., et al. (2016). Methods and approaches to modelling the Anthropocene. Global Environmental Change, 39, 328-340. https://doi.org/10.1016/j. gloenvcha.2015.08.007. 
Welch, A. C., Nicholls, R. J., \& Lázár, A. N. (2017), Evolving deltas: Co-evolution with engineered interventions. Elementa Science of the Anthropocene, 5, 49. https://doi.org/10.1525/elementa.128.

Woodroffe, C. N., Nicholls, R. J., Saito, Y., Chen, Z., \& Goodbred, S. L. (2006). Landscape variability and the response of Asian megadeltas to environmental change. In N. Harvey (Ed.), Global change and integrated coastal management: The Asia-Pacific region (pp. 277-314). New York, NY: Springer.

Open Access This chapter is licensed under the terms of the Creative Commons Attribution 4.0 International License (http://creativecommons. org/licenses/by/4.0/), which permits use, sharing, adaptation, distribution and reproduction in any medium or format, as long as you give appropriate credit to the original author(s) and the source, provide a link to the Creative Commons license and indicate if changes were made.

The images or other third party material in this chapter are included in the chapter's Creative Commons license, unless indicated otherwise in a credit line to the material. If material is not included in the chapter's Creative Commons license and your intended use is not permitted by statutory regulation or exceeds the permitted use, you will need to obtain permission directly from the copyright holder.

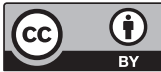

